\title{
PIDGIN AFROPORTUGUÉS DEL ATLÁNTICO
}

\section{Mario Portilla}

\section{RESUMEN}

El presente artículo establece que las lenguas criollas de base ibérica de América (saramacca, papiamento y palenquero) se encuentran relacionadas genealógicamente con los criollos portugueses de África Occidental (caboverdiano, kriol de Guinea-Bissau, saotomense, angolar, principense y annobonés). Este parentesco se comprueba mediante la comparación de varias listas de vocabulario. Este vocabulario presenta particularidades compartidas por los criollos comparados que no se hallan en el portugués estándar.

Palabras clave: Lenguas criollas, pidgin portugués, criollos ibéricos, criollos portugueses.

\begin{abstract}
In this article it is established that the Iberian-based Creole languages of South America (Saramaccan, Papiamento, and Palenquero) are genetically related to the Portuguese creoles of West Africa (Caboverndian, Guinea-Bissau Kriol, Saotomense, Angolar, Principense, and Annobonese). This kinship is confirmed by means of a comparison of several wordlists. This vocabulary shows special features shared by the compared Creoles. However, those features can not be found in standard Portuguese.
\end{abstract}

Key words: Creole languages, Portuguese pidgin, Iberian creoles, Portuguese creoles

\section{Introducción}

La colonización portuguesa de ultramar se inicia en 1417 con las expediciones marítimas promovidas por el rey Enrique el Navegante. Pocos años después, comienza la exploración y el establecimiento de fuertes comerciales en África Occidental. Posteriormente, esta exploración y colonización se extiende por otras regiones de África, por América y por Asia. Los exploradores y comerciantes portugueses utilizaron, con certeza, una especie de portugués simplificado en su interacción con la población nativa. Eventualmente, tanto la

Dr. Mario Portilla. Profesor Catedrático. Universidad de Costa Rica.

Correo electrónico: marioportilla2000@yahoo.com

Recepción: 05- 01- 2011

Aceptación: 06- 02- 2011 
población nativa de África Occidental y Asia que se concentraría alrededor de los fuertes comerciales como los esclavos enviados a América emplearon un pidgin de base portuguesa como interlengua (Whinnom 1965; Naro 1978; Perl 1989a, 1989b; Clements 1992).

Es generalmente reconocido que las lenguas criollas que se hablan en África Occidental son, de alguna forma, descendientes de este pidgin portugués. Actualmente, se hablan diversos criollos de base portuguesa en las islas de Cabo Verde, en Guinea Bissau y Senegal, en las islas Santo Tomé y Príncipe, y en la isla de Annobón, que pertenece a Guinea Ecuatorial.

Las variedades criollas de Asia se han hablado en diversos territorios: en el subcontinente indio (India y Sri Lanka), el Oriente Medio (Irán, Irak, Arabia Saudita), el sudeste asiático (Birmania, Tailandia, Malasia, Singapur, Indonesia, Timor Oriental) y China (Macao) (cf. Smith 1995). También, se ha señalado que los criollos hispánicos de Filipinas se habrían originado a partir de este pidgin portugués hablado en la región (Whinnom 1965).

Aunque todavía es materia controversial, diversos autores han considerado que el papiamento (Antillas Holandesas) (Granda 1974; Maurer 1998a; Goodman 1987; Holm 1989; McWhorter 1999), el saramacca (Suriman) (Perl et al. 1993; Bickerton 1999) y el palenquero (Colombia) (Granda 1970; Megenney 1983; Perl 1990; Schwegler 1991, 1993; Moñino 2007) también se habrían originado a partir de un pidgin portugués utilizado por los esclavos de origen africano llevados a estas regiones.

Los datos históricos parecen poner en duda que las lenguas criollas de Asia puedan realmente ser relacionadas genealógicamente con los criollos de África Occidental o de América, puesto que median aproximadamente unos cien años de diferencia entre las primeras exploraciones de África y aquellas de Asia. Por lo tanto, es muy difícil poder afirmar que estos criollos provengan de una misma variedad de portugués pidginizado (Ferraz 1987; Clements 1992).

Las evidencias lingüísticas apuntan más bien a apoyar la hipótesis de que el pidgin que originó las variedades criollas portuguesas de África Occidental era distinto del pidgin que dio origen a los criollos portugueses de Asia (Clements 1999; Bartens 1995; Stolz 1987; Lipski 2002). Clements (2000:186) postula que, a partir del año 1530, existirían por lo menos dos variedades de pidgin portugués, um mais geral que se empregava na extensa área da expansão ultramarina portuguesa, e um pidgin regional que se usava mais especificamente na Ásia.

Por otro lado, el hecho de que los portugueses mantuvieran el monopolio de la trata de esclavos hacia América hasta fines del siglo XVI y que otras naciones europeas, entre ellos los holandeses, hayan utilizado la infraestructura de los fuertes para la trata de esclavos arrebatada a los portugueses a partir de siglo XVII (Perl 1987, 1989b), permiten suponer que el papiamento, el saramacca y el palenquero provienen de un pidgin portugués, al igual que lo hacen los criollos portugueses de África Occidental.

Además, Portilla (2008a) ha mostrado que los tres criollos americanos mencionados comparten una importante cantidad de vocabulario en común, el cual muestra particularidades que solo comparten estas lenguas y que no existen en el portugués estándar (ni tampoco, por supuesto, en español) ${ }^{1}$. El autor considera que el establecimiento de esta lista constituye un indicio muy fuerte del parentesco que existe entre el papiamento, el saramacca y el palenquero.

También, mediante la comparación de una lista de unos 60 cognados establecidos, Portilla (2007 y 2008b) ha logrado la reconstrucción de los segmentos fonológicos (vocales y consonantes) de la protolengua que originó las variedades criollas americanas. También, Portilla (2009) realiza la reconstrucción de los suprasegmentales (tono y el acento) de esta misma protolengua.

Los datos históricos y demográficos disponibles permiten suponer que el papiamento se habría nativizado entre mediados del siglo XVII y principios del siglo XVIII (Kouwenberg 
\& Muyken 1995) y el saramacca lo habría hecho alrededor de 1700 (Bakker et al. 1995). Aunque no hay certeza de una fecha para la criollización del palenquero, los autores consideran que el establecimiento del Palenque de San Basilio habría ocurrido en la segunda mitad del siglo XVII con esclavos escapados de las plantaciones de los alrededores de Cartagena de Indias (Schwegler 1998; Patiño 2002). De esta forma, es posible establecer que estos tres criollos derivan de un mismo pidgin portugués que habría sido utilizado en América por lo menos entre mediados del siglo XVII y principios del siglo XVIII.

\section{Propósito de la investigación}

De acuerdo con los datos históricos y la evidencia lingüística esbozados en el apartado anterior, en esta investigación se intentará establecer si las variedades criollas de África Occidental y aquellas de América provienen de un mismo pidgin portugués. Es evidente que los criollos portugueses de África Occidental se derivan de un pidgin portugués al igual que las americanas (como el autor considera que se ha probado). Sin embargo, esta identidad en cuanto al origen del vocabulario no significa necesariamente que compartan la misma protolengua. Para que esto sea así, a juicio del autor, se deben cumplir dos condiciones. La primera es de orden histórico: el establecimiento de los criollos de África Occidental debe haber ocurrido alrededor de principios del siglo XVIII o antes de esa fecha, ya que es muy probable que los criollos americanos se nativizaran a más tardar alrededor de 1700. La segunda condición es de carácter lingüístico: tanto los criollos africanos como los americanos deben compartir particularidades que los distingan del portugués estándar y de otros criollos de base portuguesa.

Precisamente, basado en estas dos premisas, es que se puede afirmar que los criollos portugueses de Asia no están emparentados directamente con los criollos ibéricos de América ni con las lenguas criollas portuguesas de África Occidental.

Se puede ilustrar este punto con un ejemplo. Como se ha dicho, los datos históricos muestran que, con certeza, un pidgin portugués ya se habría establecido en Curazao en 1659 (Kouwenberg \& Muysken 1995: 205). También, la existencia del angolar en la isla de Santo Tomé se encuentra atestada alrededor de 1700, aunque algunos consideran que este ya existiría desde principios del siglo XVI (Lorenzino 2007: 200). Por otro lado, si bien es cierto que los portugueses se establecieron en Macao desde 1557, el texto más antiguo de vocabulario portugués en la región, que indicaría la existencia inequívoca de una variedad pidginizada, es un glosario utilizado por los chinos para fines comerciales que se remonta a 1745 (Caudemont 1993: 9). Así, pues, desde el punto de vista histórico, el papiamento y el angolar podrían estar emparentados, pero el macaense parece haberse establecido en una época posterior.

Desde el punto de vista puramente lingüístico, la sola comparación de algunos rubros de estas tres variedades muestra que la variedad portuguesa de Asia es diferente de aquellas de África y de América².

$\begin{array}{lllll}\text { Papiamento } & \text { Angolar } & \text { Macaense } & \text { Portugués } & \\ \text { 'áwa } & \text { áwá } & \text { águ } & \text { 'agua' } & \text { agua } \\ \text { 'pálu } & \text { pó } & \text { árve } & \text { 'árvore' } & \text { árbol } \\ \text { 'muhé } & \text { méngai } & \text { mulé } & \text { 'mulher' } & \text { mujer } \\ \text { 'yú } & \text { móӨu } & \text { kyása } & \text { 'criança' } & \text { niño } \\ \text { 'wówo } & \text { wé } & \text { ólu } & \text { 'olho' } & \text { ojo }\end{array}$


Es evidente que la lista anterior no indica tampoco un parentesco aparente entre ninguno de los tres criollos comparados ni ninguna particularidad que los relacione entre sí (con excepción, por supuesto, del hecho de tratarse de rubros de origen ibérico). Sin embargo, la comparación de estos mismos rubros entre el papiá kristáng (Malasia), el portugués de Korlai (India) y el macaense (China) pone en evidencia la cercanía genealógica de las variedades criollas asiáticas y sus diferencias respecto del portugués estándar.

$\begin{array}{llllll}\text { Papiá K } & \text { Korlai } & \text { Macaense } & \text { Portugués } & & \\ \text { águ } & \text { ag } & \text { águ } & \text { 'agua' } & \text { /'agua/ } & \text { agua } \\ \text { álbi } & \text { alb } & \text { árve } & \text { 'árvore' } & \text { /'arvore/ } & \text { árbol } \\ \text { mulé } & \text { muler } & \text { mulé } & \text { 'mulher' } & \text { /mu'Ker/ } & \text { mujer } \\ \text { krénsa } & \text { krians } & \text { kyása } & \text { 'criança' } & \text { /kri'âsa/ } & \text { niño } \\ \text { ólu } & \text { ol } & \text { ólu } & \text { 'olho' } & \text { /'oKu/ } & \text { ojo }\end{array}$

Entonces, en primer lugar, se relatará una breve cronología de la expansión portuguesa en África Occidental con el fin de encontrar alguna correspondencia con el establecimiento del pidgin portugués en América, tal como ha sido mencionado. En segundo lugar, se intentará establecer si existe un vocabulario común presente en las variedades africanas y las americanas, que muestre particularidades significativas compartidas solamente por ellas y que las diferencien del portugués estándar.

\section{Las lenguas criollas de base portuguesa en África}

Los navegantes portugueses visitaron las costas de África Occidental ya en la primera mitad del siglo XV. En 1456, fueron descubiertas las Islas de Cabo Verde. La ciudad de Santiago (Islas de Sotavento) fue fundada allí en 1462 y poblada con esclavos de diversas etnias traídos del continente, especialmente hablantes de wolof, lebu, fulfulde (familia atlántica), mandika y bambara (familia mende) (Parkvall 2000: 133). Hasta 1640 esta ciudad sirvió de depósito de los esclavos africanos que serían enviados a América. San Vicente (Islas de Barlovento) fue colonizada a partir de 1794 con pobladores portugueses provenientes de Portugal y de las Islas Azores.

Durante los siglos XVIII y XIX, hubo descensos drásticos de la población debido a sequías. En general, las islas de Barlovento fueron repobladas con más colonos blancos que las Islas de Sotavento.

Actualmente, los autores aceptan que el criollo portugués hablado en las Islas de Sotavento constituye una variedad lingüística bien diferenciada respecto del que se encuentra en las Islas de Barlavento (cf. Clements 2000).

Por otra parte, históricamente, el contacto entre las Islas de Cabo Verde y el territorio de Guinea-Bissau fue siempre constante, ya que ambas regiones constituyeron una sola unidad administrativa hasta mediados del siglo XIX. Según Thiele (1991), el criollo de Cabo Verde (Sotavento) fue utilizado como medio de comunicación común en el continente africano desde el siglo XVI.

En 1470, es fundada la ciudad de Cacheu en el Golfo de Guinea (actual Guinea-Bissau) y convertida en Capitanía General en 1630. Bissau se funda en 1588. En 1644, se inician los primeros embarques directos de esclavos desde Cacheu y Bissau hacia Brasil. Desde mediados del siglo XVIII, Bissau es la ciudad más importante de la Colonia portuguesa en la región. En 1859, Boloma es nombrada capital. Solo hasta 1941 Bissau es convertida en capital de la Colonia. 
En Guinea-Bissau, se pueden distinguir tres variedades dialectales: la de Cacheu y Santo Domingo, la de Bissau y Bolama y la de Bafatá y Geba. El criollo de Casamance (Casamansa o Casamanza) en Senegal (ciudad primero portuguesa, pero que forma parte de las colonias francesas desde 1836) proviene directamente de la variedad de Cacheu (Bartens 1995: 56-57).

Todo el archipiélago en el Golfo de Guinea formado por las islas de Santo Tomé, Principe y Annobón fue descubierto en el mismo viaje exploratorio en 1470-1. Sin embargo, es hasta 1485 cuando Santo Tomé es fundada como Capitanía y colonizada, convirtiéndose rápidamente en un entrepôt para el comercio de esclavos.

Durante los siglos XVI y XVII, Santo Tomé sufrió diversos ataques por parte de otras potencias coloniales europeas. Entre 1641 y 1644, por ejemplo, Santo Tomé fue dominada totalmente por los holandeses. Así, por razones de seguridad, en 1600 una importante cantidad de dueños de plantaciones portugueses emigra con sus esclavos de Santo Tomé a Brasil (Bartens 1995: 78).

Desde el siglos XVI y hasta la prohibición de la trata de esclavos, Santo Tomé funcionó como uno de los más importantes depósitos de esclavos en África Occidental. Por ello, se supone que la variedad de pidgin o criollo portugués de esta isla habría tenido una gran influencia en la formación de otras variedades criollas tanto del Golfo de Guinea como de América. Es probable que el pidgin portugués de Santo Tomé se haya estabilizado durante el siglo XVI (Hagemeijer 2009).

En el sureste de la isla de Santo Tomé, se habla otro criollo de base portuguesa, conocido como angolar. Varios autores suponen que los angolares son descendientes de esclavos cimarrones escapados de las plantaciones instaladas en esta isla desde las primeras décadas del siglo XVI. Además, parece haber sido importante para la consolidación de la población la aparición de un contingente de esclavos provenientes de Angola, que llegaron a la isla cuando se hundió allí el barco que los transportaría rumbo a América, a mediados del siglo XVI (Lorenzino 2007; Hagemeijer [por aparecer]).

Aunque las islas Príncipe y Annobón descubiertas a finales del siglo XV fueron colonizadas desde Santo Tomé a principios del siglo XVI (Hagemeijer 2009). Las relaciones administrativas entre la Isla Príncipe y Santo Tomé fueron siempre muy estrechas. En el siglo XVIII, la Isla Príncipe tuvo su apogeo como posesión colonial portuguesa. Sin embargo, a mediados del siglo XIX, hubo un descenso muy considerable de la población y, a principios del siglo XX, esta se redujo a 300 sobrevivientes de una epidemia de la enfermedad del sueño. Actualmente, la mayor parte de la población de la isla es originaria de las Islas de Cabo Verde, aunque hay descendientes de pobladores de Angola, Mozambique y Santo Tomé (Bartens 1995: 100).

Como se ha dicho, la isla de Annobón fue colonizada desde Santo Tomé y se supone que el criollo portugués de esta isla proviene directamente de un pidgin o criollo utilizado en Santo Tomé. En 1777, Portugal cedió Annobón a España. Esta isla permaneció en manos españolas hasta su independencia en 1968.

\section{El papiamento, el saramacca y el palenquero}

El origen del vocabulario portugués tanto el papiamento como en el saramacca ha sido muy controvertido. La historia del desarrollo de estos criollos es también complicada.

Aunque los españoles colonizaron primero las llamadas Islas ABC (Aruba, Bonaire

y Curazao) a principios del siglo XVI, los holandeses les arrebataron estas islas en 1634. La importación masiva de esclavos a estas islas comenzó casi inmediatamente y, a fines del 
siglo XVIII, Curazao se había convertido en el depósito de esclavos más importante de toda América. Dos terceras partes de los esclavos traídos a Curazao provenían de la Costa de los Esclavos, sobre todo de Elmina en Ghana. El predominio de los bantúes parece haber sido significativo (Bartens 1995: 246, Parkvall 2000:137).

En 1659, hubo una importante inmigración de judíos sefarditas provenientes especialmente del nordeste de Brasil, quienes habrían llevado consigo a sus esclavos. Es de suponer que estos esclavos dominarían algún tipo de pidgin afroportugués.

Se considera que, probablemente, el papiamento se habría criollizado en Curazao entre 1650 y 1700 (Bartens 1995: 247; Kouwenberg \& Muysken 1995: 205). De allí fue transladado a Bonaire alrededor de 1700 y a Aruba a fines del siglo XVIII (Bartens 1995: 247). El vocabulario de lenguas africanas es muy reducido. Los pocos términos reconocidos provienen principalmente del kikongo (familia niger-congo, grupo bantoide) y del fon (familia nigercongo, grupo gbe) (Maurer 1998a).

El saramacca es una lengua de los descendientes de esclavos cimarrones hablada en Surinam. La llegada de los ingleses a Surinam se remonta a 1630, pero esta región fue colonizada a partir de 1651 desde la isla de Barbados. Surinam permaneció como posesión inglesa hasta 1667, cuando la colonia fue cedida a los holandeses. Entre 1664 y 1665, los judíos sefarditas refugiados del nordeste de Brasil se establecieron como colonos. Estos colonos, como se ha dicho, habrían llevado consigo a sus esclavos, quienes presumiblemente tendrían algún conocimiento de un pidgin afroportugués. Hubo en esta colonia también una relativa proponderancia de esclavos provenientes de la Costa de los Esclavos y una presencia abundante de bantúes sobre todo antes de entrado el siglo XVIII (Bartens 1995: 238; Parkvall 2000: 126).

Al parecer, el origen de la comunidad de los saramaccas se remonta al 1690 con el escape masivo de esclavos de la plantación de Inmauel Machado. Se supone que desde su surgimiento el saramacca habría estado muy influido por la variedad lingüística empleada por los esclavos cimarrones huidos de las plantaciones de los judíos sefarditas desde finales del siglo XVII (Bakker et al. 1995: 168-9). Se considera que la criollización del saramacca debió haber ocurrido entonces cerca del 1700 (Bartens 1995: 238).

El vocabulario de lenguas africanas en el saramacca alcanza hasta el 4\% (Bartens 1995: 244). Este proviene fundamentalmente de lenguas de la familia niger-congo, del grupo bantoide, especialmente del kikongo y del grupo gbe, como el fon y el ewe (Good 2009; Bartens 1995: 238; Bakker et al. 1995: 170).

La primera noticia de la existencia del Palenque de San Basilio (que se encuentra a unos 80 kilómetros al sur de Cartagena de Indias) se remonta a 1713 (Friedemann \& Patiño 1983: 43). Sin embargo, se supone que esta población ya existiría, por lo menos, desde mediados del siglo XVI cuando habría sido fundada por esclavos cimarrones escapados de plantaciones cercanas a Cartagena (Schwegler 1998: 223).

Cartagena fue uno de los puertos principales, junto con Salvador de Bahía, Brasil y Veracruz, en México, para la trata de esclavos en América, sobre todo en una etapa inicial (Perl 1998b: 16). En 1627, el padre Alonso Sandoval menciona que los esclavos traídos a Cartagena desde la isla de Santo Tomé se entendían entre sí por medio de una forma de pidgin portugués (Granda 1970; Megennney 1986: 72; Schwegler 1998:229).

\footnotetext{
Y los llamados criollos y naturales de San Thomé, con comunicación que con tan bárbaras y recónditas naciones han tenido el tiempo que han residido en San Thomé, las entienden casi todas con un género de lenguaje muy corrupto y revesado de la portuguesa, que llaman lengua de San Thomé, al modo que ahora
} 
nosotros entendemos y hablamos con todo género de negros y naciones con nuestra lengua española corrupta, como comúnmente la hablan todos los negros. (Alonso de Sandoval 1627 De instauranda Aethiopum salute. Citado por Megenny 1983: 72)

La referencia explícita al habla de Santo Tomé ha sido considerada como un claro indicio de la relación genealógica del palenquero con el criollo hablado en esta isla.

Al igual que en el caso del papiamento y el saramacca, parece que hubo un predominio de hablantes de lenguas bantúes en la comunidad palenquera, especialmente de kikongo y en menor medida de kimbundu. Aunque en un principio y alrededor de 1580, la mayor parte de los esclavos llevados a Colombia eran hablantes de wolof (familia senegambiense), entre 1580 y 1650, la proporción de hablantes de lenguas bantúes llega a un 95\% (Parkvall 2000: 137). La mayor parte de los términos de origen africano conservados en esta lengua se derivan del kikongo (Schwegler 2002, 2006).

\section{Las variedades comparadas}

La mayor parte de los autores distinguen las siguientes variedades de lenguas criollas portuguesas (Cf. v. gr. Smith 1995):

1. Los criollos de la Alta Guinea:

1.1. Islas de Cabo Verde: Caboverdiano (variedades de las Islas de Sotavento y de las islas de Barlovento).

1.2. Guinea-Bissau y Senegal: Kriol, denominado también kriyol, criol, guineano, crioulo da Guiné (tres dialectos: Bissau y Bolama; Batafa; Cacheu y Casamance).

2. Los criollos del Golfo de Guinea:

\subsection{Isla Santo Tomé:}

2.1.1. Saotomense, denominado también forró, lungwa santomé.

2.1.2. Angolar, denominado también lunga ngolá, moncó.

2.2. Isla Príncipe: Principense, denominado también lunguyé, lungu'ie.

2.3. Isla Annobón: Annobonés, denominado también fá d’ambú, pagalu.

Los autores clasifican los criollos portugueses de África Occidental en dos grandes grupos: los de la Alta Guinea y los del Golfo de Guinea, no solo por su ubicación geográfica, sino también basados en su relaciones genealógicas (cf. Hagemeijer [por aparecer]).

Para este estudio, se tomarán en cuenta las siguientes variedades de África Occidental: el caboverdiano (variedad de Santiago, Islas de Sotavento) (Quint-Abrial 1998; Graham \& Graham 2003; Lopes da Silva 1957), el kriol de Guinea-Bissau (Scantamburlo 1981), el saotomense (Mané 2007; Graham \& Graham 2003), el angolar (Maurer1995; Mané 2007, Graham \& Graham 2003) el principense (Mané 2007; Graham \& Graham 2003) y el annobonés (Mané 2007; Graham \& Graham 2003).

Además, se consideran también para la comparación los tres criollos con vocabulario ibérico de América: el papiamento (Maurer 1998B; Maduro 1987; Papiamento-English/EnglishPapiamento lexicon, Amaro's papiamentu project), el saramacca (Huttar 1972, SaramaccanEnglish Dictionary del SIL) y el palenquero (Maduro 1987; Cásseres 2005; Megenny 1986; Friedemann \& Patiño 1983). También, se utilizan los rubros del pidgin afroportugués americano (PPA) como ha sido reconstruido en Portilla (2007, 2008a, 2008b, 2009). 


\section{El protopidgin afroportugués americano}

Como se ha dicho, Portilla (2008a) estableció una lista de vocabulario compartido por los tres criollos ibéricos americanos, el cual es divergente del portugués estándar. Según el autor, esta lista constituye un indicio muy fuerte del parentesco entre papiamento, el saramacca y el palenquero, y de la existencia misma de un pidgin portugués utilizado en América, que habría constituido la protolengua antecesora de estos criollos.

Para una comparación posterior, se presenta a continuación esta lista de 32 rubros, que es una versión revisada de la que aparece en Portilla (2008a). En ella, aparece primero la forma reconstruida del rubro (la protoforma), seguida de los cognados en los tres criollos comparados y de la palabra en portugués estándar moderno. La reconstrucción de las protoformas está basada en las correspondencias fonológicas sistemáticas establecidas en Portilla (2007, 2008b, 2009).

\section{Lista de vocabulario singular del pidgin afroportugués americano (PPA) ${ }^{3}$}

\begin{tabular}{|c|c|c|c|c|c|}
\hline$P A A$ & Saramacca & Papiamento & Palenquero & Portugués & \\
\hline *arí & ---- & 'arí & arí & 'rir' & reír \\
\hline *bái & ---- & 'bái & báe & ‘ir’ & ir \\
\hline *barí & baí & 'barí & ----- & ‘varrer' & barrer \\
\hline *barí ka & baí ka & ba'rí ka & baríka & 'barriga' & barriga \\
\hline *buníta & 'bunîta' 4 & bu'níta & ----- & 'bonito' & bonito \\
\hline *dentrá & dendá & 'drentá & lendrá & 'entrar’ & entrar \\
\hline *didía & didía & di'día & ----- & 'dia’ & día \\
\hline *drumí & duumí & 'drumí & drumí & 'dormir' & dormir \\
\hline *fregá & feegá & 'fregá & fregá & 'esfregar' & fregar \\
\hline *ganá & gaján & 'gajá & ---- & 'enaganar' & engañar \\
\hline *gulí & gulí & 'gulí & ---- & 'engolir’ & engullir \\
\hline *gumbitá & gumbitá & 'gumbitá & ----- & 'vomitar' & vomitar \\
\hline *kabá & kabá & 'kabá & kabá & 'acabar' & acabar \\
\hline *katí bu & katí bo & ka'tí bu & ----- & 'escravo' & esclavo \\
\hline *kobá & ----- & 'kobá & kobá & 'cavar’ & cavar \\
\hline *ku & $\mathrm{ku}$ & $\mathrm{ku}$ & $\mathrm{ku}$ & ‘com’ & con \\
\hline *landá & landá & 'landá & ----- & ‘nadar’ & nadar \\
\hline *lembé & lembé & 'lembé & ----- & 'lamber’ & lamer \\
\hline *mará & ----- & 'mará & malá & 'amarrar’ & amarrar \\
\hline *mi & $\mathrm{mi}$ & $\mathrm{mi}$ & ----- & ‘eu’ & yo \\
\hline *na & na & na & ----- & 'em, no, na' & en \\
\hline *oló $\mathrm{i}$ i & olóísi & o'lófi & ----- & ‘relógio’ & reloj \\
\hline *papagái & papakái & papa'gái & ----- & 'papagaio' & papagayo \\
\hline *pruntá & --- & 'puntra & plundá & 'perguntar' & preguntar \\
\hline *ranká & ---- & 'ranká & lanká & 'arrancar' & arrancar \\
\hline *rí ba & lí ba & 'rí ba & rí ba & 'riba' (adv.) & sobre \\
\hline *rumán & ---- & ru'mán & numán $(\mathrm{o})^{5}$ & ‘irmão’ & hermano \\
\hline & sábi & 'sabi & ----- & ‘saber’ & saber \\
\hline
\end{tabular}




$\begin{array}{llllll}\text { *sendé } & \text { sendé } & \text { 'sendé } & ----- & \text { 'acender' } & \text { encender } \\ \text { *sukúru } & \text { sugúu } & \text { 'suku } & ---- & \text { 'escuro' } & \text { oscuro } \\ \text { *té } & \text { té } & \text { 'té } & ---- & \text { 'até' } & \text { hasta } \\ \text { *tén } & ----- & \text { 'tin } & \text { tén } & \text { 'ter' } & \text { haber, tener }\end{array}$

Por supuesto, muchos de los rubros reconstruidos corresponden a formas subestandarizadas que han sido reportadas en el habla popular del mundo lusitano o se trata de formas arcaicas, las cuales no son necesariamente exclusivas de las lenguas criollas afroportuguesas. Precisamente, este hecho es muy significativo para el objetivo de este estudio pues viene a caracterizar la naturaleza de la variedad de portugués en la que se basó el pidgin que dio origen a estas tres lenguas. Por eso, lo más significativo es que estas variedades comparten estas singularidades.

Por otro lado, se debe mencionar que estas lenguas, especialmente el saramacca y el papiamento, presentan otros rubros de un claro origen portugués que también son divergentes respecto del estándar. Estos no se no incluyeron en la lista porque no se encontraron cognados en, por lo menos, dos de las lenguas comparadas, pero serán presentadas en otro apartado (vid. infra).

\section{El vocabulario compartido por los criollos portugueses de África Occidental y el pidgin afroportugués americano}

Primeramente, se presenta a continuación una lista con los rubros reconstruidos del pidgin afroportugués americano (PAA) que tienen cognados en una o varias lenguas criollas portuguesas de África Occidental. Estos términos corresponden a 27 cognados de un total de 32 que habían sido establecidos para las variedades criollas americanas ${ }^{6}$.

1. Reír: port. 'rir'

$\begin{array}{lllllll}P P A & C V^{7} & G B^{8} & S T & A N G^{9} & P R^{10} & A N N \\ \text { *arí } & \text { 'ari } & \text { li } & \text { li } & \text { li } & \text { are } & \text { li }\end{array}$

De las lenguas criollas portuguesas de África Occidental, solamente el caboverdiano y el principense presentan términos cognados con el pidgin afroportugués americano. Estos rubros muestran una vocal protética inesperada acuerdo con el étimo latino (ridere). Las palabras cognadas parecen ser, sin embargo, formas ya obsolescentes en caboverdiano y principense.

2. Ir: port. 'ir'

$\begin{array}{lllllll}P P A & C V & G B^{11} & S T^{12} & A N G^{13} & P R^{14} & A N N \\ \text { *bái } & \text { 'bai } & \text { bai } & \text { be } & \text { be } & \text { we } & \text { bai }\end{array}$

Todos los rubros provienen de la forma verbal de tercera persona singular vai y no del infinitivo ir (< lat. ire). Esta es una derivación irregular ya que la gran mayoría de los verbos provienen del infinitivo en estas lenguas criollas. Además, todos los criollos presentan una consonante bilabial en vez de una labiodental como sucede en portugués estándar.

3. Barrer: port. 'varrer'

$\begin{array}{lllllll}P P A & C V & G B & S T & A N G & P R & A N N \\ \text { *barí } & \text { 'bari } & \text { bari } & \text { bali } & \text { bari } & ---- & \text {---- }\end{array}$


Esta forma muestra una irregularidad en la vocal temática final de acuerdo con el étimo latino (varrere).

4. Entrar: port. 'entrar'

$\begin{array}{lllllll}P P A & C V & G B & S T & A N G & P R & A N N \\ \text { *dentrá } & \text { 'entra } & \text { entra } & \text { lentla } & \text { letfia } & \text { lenta } & \text { lentela }\end{array}$

Actualmente, la forma dentrar todavía persiste en algunas zonas rurales de hispanoamérica, pero es considerada vulgar. Presumiblemente, en español y portugués, esta palabra provendría de la protoforma *dentrar, que se derivaría del verbo entrar $(<$ lat. intrare) influido por el adverbio dentro (< lat. de + intro).

5. Dormir: port. 'dormir'

$\begin{array}{lllllll}P P A & C V^{15} & G B & S T^{16} & A N G^{17} & P R & A N N \\ \text { *drumí } & \text { 'drumi } & \text { durmi } & \text { dromini } & \text { dumi } & \text { dimi } & \text { dziumi }\end{array}$

Los rubros emparentados presentan una metátesis respecto del étimo portugués (< lat. dormire).

6. Fregar: port. 'esfregar'

$\begin{array}{lllllll}P P A & C V & G B & S T & A N G & P R & A N N \\ \text { *fregá } & \text { 'frega } & \text { ferga } & \text { flega } & \text { fega } & \text { fega } & ----\end{array}$

Los términos presentan una aféresis de la sílaba inicial respecto del portugués esfregar $(<$ lat. ex + fricare $)$.

7. Engullir: port. 'engolir'

$\begin{array}{lllllll}P P A & C V & G B & S T & A N G & P R & A N N \\ \text { *gulí } & \text { 'yguli } & --- & \text { gguli } & \text { yguri } & \text { guli } & \text {---- }\end{array}$

Los rubros presentan una aféresis respecto del étimo portugués original engolir $(<$ en 'dentro' + gola 'cuello' < lat. gula 'garganta').

8. Vomitar: port. 'vomitar'

\begin{tabular}{|c|c|c|c|c|c|}
\hline $\begin{array}{l}P P A \\
\text { * qumbitá }\end{array}$ & $\begin{array}{l}C V^{18} \\
\text { qu'mita }\end{array}$ & $\begin{array}{l}G B \\
\text { qumita }\end{array}$ & $\begin{array}{l}S T^{19} \\
\text { nqumita }\end{array}$ & $\begin{array}{l}A N G \\
\text { nqumita }\end{array}$ & $\begin{array}{l}P R \\
----\end{array}$ \\
\hline
\end{tabular}

Las formas portuguesas tanto vomitar como gomitar provienen del latín vomitare, frecuentativo de vomire. Ambas formas alternan en portugués y son consideradas prestigiosas hasta el siglo XVII, cuando gomitar empieza a ser tomado como un vulgarismo.

9. Acabar: port. 'acabar'

$\begin{array}{lllllll}P P A & C V & G B & S T & A N G & P R & A N N^{20} \\ \text { *kabá } & \text { 'kaba } & \text { kaba } & \text { kaba } & \text { kaba } & \text { kaba } & \text { kaba }\end{array}$


Los rubros criollos presentan una aféresis de la vocal inicial de acuerdo con el étimo portugués original acabar (literalmente 'llevar algo al cabo'). El verbo se deriva del nombre cabo 'extremo', del latín caput 'cabeza'.

10. Esclavo: port. 'escravo'

$\begin{array}{lllllll}P P A & C V & G B & S T & A N G & P R & A N N \\ \text { *katí bu } & \text { ka'tibu } & \text { katibu } & ---- & ---- & ---- & ----\end{array}$

Estos cognados presentan un significado idéntico que difiere del portugués estándar cativo 'cautivo'. Además, muestran el cambio fonológico desde el portugués / v / > / b /.

11. Cavar: port. 'cavar'

$\begin{array}{lllllll}P P A & C V & G B & S T & A N G & P R & A N N \\ \text { *kobá } & \text { 'koba } & \text { koba } & ---- & \text { vina } & ---- & ----\end{array}$

El verbo portugués covar se deriva del nombre latino covus 'hueco', que es una variante arcaica de cavus 'idem', de donde proviene el rubro del portugués estándar.

12. Con: port. 'com, y'

$\begin{array}{lllllll}P P A & C V & G B & S T & A N G{ }^{21} & P R & A N N \\ * \mathbf{k u} & \mathbf{k u} & \mathbf{k u} & \mathbf{k u} & \mathbf{k u} & \mathrm{ki} & \mathbf{k u}\end{array}$

Las formas criollas presentan una ausencia de nasalidad respecto del étimo portugués estándar com (< lat. cum). Además, muy significativamente, esta palabra se utiliza no solo con un significado preposicional sino que también sirve de conjunción copulativa ${ }^{22}$.

13. Nadar: port. 'nadar'

$\begin{array}{lllllll}P P A & C V & G B^{23} & S T^{24} & A N G{ }^{25} & P R & A N N \\ \text { *landá } & \text { 'nada } & \text { lanta } & \text { landa } & \text { landa } & \text { lada } & ----\end{array}$

Los rubros cognados presentan tanto una nasal inesperada según el étimo portugués nadar (< lat. natare) como el cambio / $\mathrm{n} />/ 1 /$.

14. Lamer: port. 'lamber'

$\begin{array}{lllllll}P P A & C V^{26} & G B & S T & A N G & P R & A N N \\ \text { *lembé } & \text { 'lembe } & \text { limbi } & ---- & \text { lolo } & ---- & ----\end{array}$

Las formas criollas emparentadas presentan una asimilación vocálica inexistente en el étimo portugués original lamber (< lat. lambere).

15. Amarrar: port. 'amarrar'

$\begin{array}{lllllll}P P A & C V & G B & S T & A N G{ }^{27} & P R & A N N \\ \text { *mará } & \text { mara } & \text { mara } & \text { mala } & \text { maa } & \text { mara } & \text {----- }\end{array}$

Los rubros criollos presentan una aféresis respecto del rubro portugués estándar amarrar, el cual proviene del francés amarrer y este del neerlandés aamarren 'atar'. 
16. Yo: port. 'eu'

$\begin{array}{lllllll}\text { PPA } & C V & G B & S T & A N G & P R & A N N \\ \text { * mi } & \mathbf{m i} & \mathbf{m} & \mathbf{m} & \mathbf{m} & ---- & \mathbf{m i}\end{array}$

Las formas criollas provienen del pronombre personal de objeto en portugués mim (< lat. vulgar $m i<$ lat. clásico mihi).

17. Preposición locativa general: port. 'em, na, no'

$\begin{array}{lllllll}\text { PPA } & C V & G B & S T & A N G & P R & A N N \\ \text { *na } & \text { na } & \text { na } & ---- & ---- & ---- & ----\end{array}$

En los criollos, esta palabra es una preposición locativa invariable de carácter general. Proviene de la preposición contracta del portugués $n a<\mathrm{em}+\mathrm{a}$ 'en la'.

18. Reloj: port. 'relógio'

$\begin{array}{lllllll}P P A & C V & G B^{28} & S T & A N G & P R & A N N \\ \text { *olófi } & --- & \text { orlod3u, } & ---- & \text { loloðu } & ---- & ---\end{array}$

Los rubros criollos presentan una forma más arcaica que la actual portuguesa (del catalán relotge). Esta proviene de una palabra más antigua en catalán arolotge (1368), que conserva la vocal / o / etimológica de la palabra latina horologium (Corominas 1983).

19. Papagayo: port. 'papagaio'

$\begin{array}{lllllll}P P A & C V & G B & S T & A N G & P R & A N N \\ \text { *papagái } & \text { papa'gaju } & \text { papagaja } & \text { papage } & \text { panpage } & \text { page } & \text {---- }\end{array}$

Los términos emparentados representan una forma más arcaica que la actual del portugués estándar papagaio. Aunque el origen de esta palabra es un poco incierto, parece que proviene del árabe babagâ, el cual ingresó a las lenguas de la península ibérica a través del occitano papagai (Corominas 1983).

20. Preguntar: port. 'perguntar'

$\begin{array}{lllllll}P P A & C V & G B^{29} & S T & A N G{ }^{30} & P R & A N N \\ \text { * puntrá } & \text { pur'gunta } & \text { punta } & \text { punta } & \text { puta } & \text { mputa } & \text {---- }\end{array}$

Todos los rubros criollos pueden obtenerse de la siguiente derivación desde una supuesta forma particular del portugués con una asimilación vocálica *purguntá > *puruguntá $>$ *pruuntá $>$ *puuntrá $>$ *puntrá $>$ punta, pũ ta, puta, mputa. La palabra en portugués proviene del latín vulgar praecunctare y esta del clásico percontari (Corominas 1983).

21. Arrancar: port. 'arrancar'

$\begin{array}{lllllll}P P A & C V & G B & S T & A N G & P R & A N N \\ \text { *ranká } & \text { 'ranka } & \text { rinka } & \text { lanka } & \text { lanka } & \text { ranka } & \text {---- }\end{array}$


Los términos criollos presentan una aféresis respecto del étimo portugués arrancar, probablemente se deriva del catalán arrencar 'desbandar, vencer'.

22. Sobre: port. 'sobre, em cima'

$\begin{array}{lllllll}P P A & C V & G B & S T & A N G{ }^{31} & P R & A N N \\ \text { *ríba } & \text { riba } & \text { riba } & \text { liba } & \text { ríba } & ---- & \text { liba }\end{array}$

En portugués, este rubro se utiliza en frases con carácter más bien adverbial como en em riba 'arriba'. Su uso como preposición es desconocido en portugués estándar. Como sustantivo proviene del latín ripam 'orilla'.

23. Hermano: port. 'irmão'

$\begin{array}{lllllll}P P A & C V^{32} & G B & S T & A N G^{33} & P R & A N N^{34} \\ \text { *rumán } & \text { ir'mon } & \text { ermon } & \text { lumon } & \text { lumon } & \text { rima } & \text { nam }\end{array}$

Las formas criollas de los criollos americanos y del Golfo de Guinea presentan, respecto del portugués, primero, una aféresis de la vocal inicial / i / y luego la introducción de una vocal epentética. El étimo portugués irmão proviene del latín germanum.

24. Encender: port. 'acender'

$\begin{array}{lllllll}P P A & C V^{35} & G B & S T & A N G & P R & A N N \\ \text { *sendé } & \text { 'sende } & \text { sindi } & ---- & \text { 日ende } & ---- & ---\end{array}$

Los rubros criollos presentan una aféresis respecto del étimo portugués estándar acender (< lat. incendere).

25. Oscuro: port. 'escuro'

$\begin{array}{lllllll}P P A & C V & G B & S T & A N G & P R & A N N \\ \text { *sukúru } & \text { su'kuru } & \text { sukuru } & \text { kuru } & \text { sisima } & \text { ukuru } & ----\end{array}$

Los términos emparentados del pidgin afroportugués americano y de los criollos de la Alta Guinea muestran tanto una aféresis de la vocal inicial / e / como una epéntesis vocálica respecto del rubro portugués estándar. Se propone la siguiente derivación: port. escuro > *skúru > *sukúru, su'kuru.

26. Hasta: port. 'até'

$\begin{array}{lllllll}P P A & C V & G B^{36} & S T & A N G & P R & A N N^{37} \\ \text { *té } & \text { 'ti } & \text { te } & ---- & \text { ate } & \text { ten } & \text { ata }\end{array}$

Las formas criollas emparentadas han sufrido una aféresis vocálica respecto del étimo portugués até (< árabe háttà).

27. Haber: port. 'haver, ter'

$\begin{array}{lllllll}P P A & C V & G B & S T & A N G{ }^{38} & P R & A N N \\ \text { *tén } & \text { 'ten } & \text { ten } & \text { te } & \text { te } & \text { te } & \text { te }\end{array}$


Los rubros criollos se derivan, de manera irregular, de la forma verbal conjugada en tercera persona singular tem y no del infinitivo portugués ter $(<$ lat. tenere).

Por otro lado, los rubros de la lista de formas peculiares reconstruidas para el pidgin afroportugués americano establecidas en Portilla (2008a) que no presentan cognados con los criollos portugueses de África Occidental es la siguiente:

1. Barriga: port. 'barriga'

$\begin{array}{lllllll}P P A & C V & G B & S T & A N G & P R & A N N \\ \text { *barí ka } & \text { ba'riga } & \text { bariga } & \text { bega } & \text { bé́gá } & \text { buega } & \text { bega }\end{array}$

La protoforma americana/*baríka/ difiere de los términos de todos los criollos africanos. Esta protoforma americana parece ser más conservadora, ya que los rubros portugueses tanto barrica como barriga provienen del gascón barrique (<*barrica), que, en última instancia, parece ser de origen galo (Corominas 1983). La forma barrica es subestándar y, por ello, carece de autoridades. Es registrada apenas en el siglo XIX (Corominas 1983, Machado 1956). También, los rubros de los criollos del Golfo de Guinea muestran una forma divergente (*beléga) de aquella de los criollos de la Alta Guinea (*ba'riga). Obviamente, esta última forma es muy afín al portugués.

2. Bonito: port. 'bonito'

$\begin{array}{lllllll}P P A & C V & G B & S T & A N G & P R & A N N \\ \text { *buníta } & \text { bu'nítu } & \text { bonitu } & ---- & \text { juka(ru) } & ----- & \text {---- }\end{array}$

El término del pidgin afroportugués americano no está relacionado con los rubros de los criollos africanos, los cuales presentan una forma afín al portugués estándar. La particularidad que muestra el rubro reconstruido para el protopidgin americano es que proviene de la forma femenina del adjetivo.

3. Día: port. 'dia'

$\begin{array}{lllllll}P P A & C V & G B & S T & A N G{ }^{39} & P R & A N N \\ \text { *didía } & \text { 'dia } & \text { dia } & \text { dia } & \text { dia } & \text { dia } & \text { dia }\end{array}$

La protoforma americana no tiene cognados en ninguno de los criollos portugueses de África Occidental. Evidentemente, esta proviene de la frase de dia.

4. Engañar: port. 'enganar'

$\begin{array}{lllllll}P P A & C V & G B & S T & A N G & P R & A N N \\ \text { *gajá } & \text { 'ygana } & \text { ygana } & \text { 'li } & \text { ygana } & ----- & ----\end{array}$

Aunque todas las palabras presentan una aféresis vocálica, la protoforma reconstruida para pidgin afroportugués americano presenta una consonante nasal palatal inesperada de acuerdo con el étimo portugués enganar (< lat. innganare).

5. Saber: port. 'saber'

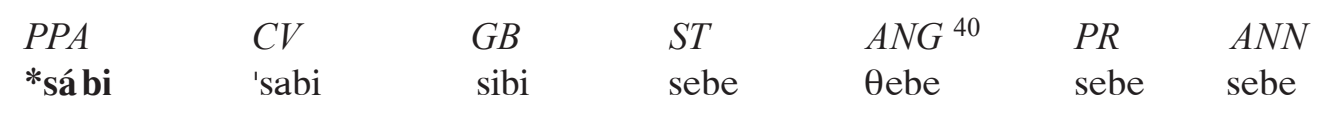


No está claro que los rubros de los criollos africanos estén emparentados directamente con el del pidgin afroportugués americano. Ni siquiera esto es seguro en el caso del caboverdiano. La particularidad que tiene esta palabra es que representa uno de los pocos verbos que llevan un tono alto en la sílaba paroxítona en el pidgin afroportugués americano. Dado que el caboverdiano siempre lleva el acento en esta posición en todos los verbos, no es posible establecer si la coincidencia del emplazamiento de los suprasegmentales en ambas lenguas se deba a una herencia común o a un cambio posterior.

\section{Vocabulario común del papiamento y el saramacca con los criollos portugueses de África Occidental}

A continuación, se presenta otra lista de vocabulario compartido entre variedades particulares de los criollos ibéricos americanos y de los criollos portugueses de África Occidental. Esta lista demuestra también el parentesco entre los criollos ibéricos de América y de África, pues contiene rubros que presentan particularidades que no existen en el portugués estándar.

\subsection{El papiamento}

1. Rey: port. 'rei'

$\begin{array}{lllllll}P A P & C V & G B & S T & A N G & P R & A N N \\ \text { a'réi } & \text { 'rei } & ---- & \text { ale } & \text { ale } & \text { are } & \text { ale }\end{array}$

Los rubros emparentados presentan una epéntesis vocálica que no ocurre en portugués rei (< lat. regis).

2. Venir: port. 'vir'

$\begin{array}{lllllll}P A P & C V & G B & S T & A N G{ }^{41} & P R & A N N^{42} \\ \text { 'bín } & \text { 'ben } & \text { bin } & \text { bi } & \text { bi } & \text { vi } & \text { bi }\end{array}$

Los rubros cognados provienen de la forma conjugada del verbo en tercera persona singular vim y no del infinitivo vir. En estas lenguas criollas, la gran mayoría de los verbos provienen del infinitivo. Además, los rubros emparentados presentan una consonante bilabial y no una labiodental como ocurre en portugués. Presumiblemente, el término en principense ha sido influido por el portugués estándar.

3. Hormiga: port. 'formiga'

$\begin{array}{lllllll}P A P & C V & G B & S T & A N G & P R & A N N \\ \text { fru'mínga } & \text { fur'minga } & \text { firminga } & \text { flominga } & \text { fominga } & ---- & \text {---- }\end{array}$

Los términos cognados del papiamento y del saotomense muestran una metátesis de la consonante líquida. Además, todos los términos comparados presentan una nasal ante la consonante velar que no predice el étimo portugués formiga.

4. Yo (enfático): port. 'eu!'

$\begin{array}{lllllll}P A P & C V & G B & S T & A N G & P R & A N N \\ \text { a'mí } & \text { a'mi } & \text { ami } & ---- & \text { am } & ---- & ---\end{array}$


Estos términos en las lenguas criollas presentan una vocal epentética que no ocurre en portugués.

5. Vos, tú: port. 'você, tu'

$\begin{array}{lllllll}P A P & C V & G B & S T & A N G 43 & P R & A N N \\ \text { bo } & \text { 'bo } & \text { bu } & --- & \text { bo } & --- & \text { bo }\end{array}$

Las formas criollas constituyen el reflejo de un arcaísmo en portugués vós (< lat. vos 'ustedes'). Además, comparten la particularidad de presentar una consonante bilabial que corresponde al fonema / v / del portugués estándar.

6. Vos, tú (enfático): port. 'você, tu!'

$\begin{array}{lllllll}P A P & C V & G B & S T & A N G & P R & A N N \\ \text { a'bó } & \text { a'bo } & ---- & ---- & ---- & ---- & ----\end{array}$

Los rubros de las lenguas criollas muestran una vocal epentética que no ocurre en portugués vós (originalmente con sentido de plural) (< lat. vos 'ustedes').

7. Sol: port. 'sol'

$\begin{array}{llllllr}P A P & C V & G B & S T & A N G & P R & A N N \\ \text { 'sólo } & \text { 'sol } & \text { sol } & \text { solo } & \text { 日olo } & \text { usolo } & \text { solo }\end{array}$

Las palabras emparentadas presentan una vocal paragógica que es inesperada según el étimo portugués estándar sol (< lat. solem).

8. Perro: port. 'cachorro, cão'

\begin{tabular}{|c|c|c|c|c|c|c|}
\hline$P A P$ & $C V$ & $G B$ & $S T$ & $A N G$ & $P R$ & $A N N^{44}$ \\
\hline ka'tfó & ka't $\int o r$ & katfur & kaso & $\operatorname{ka} \theta 0$ & kaso & zasolo \\
\hline
\end{tabular}

Los términos cognados del papiamento, saotomentse, angolar y principense presentan una apócope completa de la sílaba final del étimo portugués original cachorro 'cría del perro' (< lat. vulgar *cattulum < lat. clásico catulum 'cachorro').

9. Levantar: port. 'levantar'

$\begin{array}{lllllll}P A P & C V & G B & S T & A N G & P R & A N N^{45} \\ \text { 'lantá } & \text { la'banta } & \text { labanta } & \text { lanta } & \text { lanta } & \text { lanta } & \text { lanta }\end{array}$

Los rubros emparentados presentan la síncopa de la segunda sílaba respecto del término en portugués estándar levantar ( *levantar < lat. levar influido por el tema de su forma participial levans, levantis ). Todos los criollos muestran una asimilación de la vocal en la primera sílaba.

\subsection{El saramacca}

1. Allá: port. 'lá'

$\begin{array}{lllllll}S A R & C V & G B & S T & A N G \text { 46 } & P R & A N N \\ \text { alá } & \text { a'la } & \text { 'la } & ---- & \text { na } & ---- & \text { la }\end{array}$


Los términos del saramacca y del caboverdiano representan reflejos de una forma arcaica en portugués que conserva la vocal inicial, alá (< lat. illac).

2. Ombligo: port. 'umbigo'

$\begin{array}{lllllll}S A R & C V & G B & S T & A N G & P R & A N N \\ \text { bíngo } & \text { 'biku } & \text { biku } & \text { binku } & \text { mbiku } & \text { bigu } & \text { or }\end{array}$

En algunos de los criollos de África Occidental, el étimo portugués umbigo 'ombligo' (< lat. umbilicum) parece haberse confundido con la forma bico 'pico, tetilla' (< lat. beccus 'pico de ave'): kriol de Guinea-Bissau / biku di bariga / 'ombligo', / biku di mama / 'pezón'. Esto explicaría la presencia irregular de la consonante velar sorda en estas lenguas. De cualquier forma, todas las variedades presentan una aféresis de la vocal inicial. El saramacca y saotomense muestran, además, una nasal inesperada según étimo portugués original.

3. Aborrecer: port. 'aborrecer'

\begin{tabular}{|c|c|c|c|c|c|}
\hline$S A R^{48}$ & $C V$ & $G B$ & $S T$ & $A N G$ & $P R$ \\
\hline 'brusséh' & ----- & ---- & blose & bote & ---- \\
\hline
\end{tabular}

Los rubros criollos presentan una aféresis vocálica respecto de la forma original en portugués aborrecer (< lat. tardío abhorrescere 'erizarse, evitar'). Y más significativamente aún, muestran una metátesis entre la primera vocal y la líquida $(r / 1+u / \rho>u / o+r / l)$ respecto del étimo portugués, tanto en saramacca como en saotomense.

4. Abrir: port. 'abrir'

$\begin{array}{ccccccc}S A R & C V & G B^{49} & S T & A N G & P R & A N N^{50} \\ \text { jabí } & \text { 'abri } & \text { jabri } & \text { bili } & \text { biri } & \text { bii } & \text { bi }\end{array}$

El saramacca y el kriol de Guinea-Bissau presentan una la consonante / j / protética antes de la vocal del étimo portugués abrir (< lat. aperire).

5. Asar: port. 'assar'

$\begin{array}{lllllll}S A R & C V & G B & S T & A N G & P R & A N N \\ \text { jasá } & \text { 'sa } & \text { jasa } & \text { as } & \theta \mathrm{a} & \text { se } & \text { as }\end{array}$

De nuevo, el saramacca y el kriol de Guinea-Bissau presentan una consonante / j / protética antes de la vocal del étimo portugués assar (< lat. assare).

6. Escoger: port. 'escolher'

$\begin{array}{lllllll}S A R & C V^{51} & G B & S T & A N G & P R & A N N \\ \text { 'kujeh' } & \text { 'skodze } & \text { kud3i } & \text { koje } & \text { koje } & ---- & \text {---- }\end{array}$

Las palabras emparentadas muestran una aférisis de la primera sílaba respecto del étimo portugués escolher (< lat. ex + colligere). 
7. Agarrar: port. 'apanhar'

$\begin{array}{lllllll}S A R & C V & G B & S T & A N G & P R & A N N \\ \text { paján } & \text { 'pana } & \text { paja } & \text { paja } & \text { paja } & \text { paja } & ---\end{array}$

Las palabras emparentadas muestran una aféresis vocálica respecto del étimo portugués apanhar.

8. Espantar: port. 'espantar'

$\begin{array}{lllllll}S A R & C V & G B^{52} & S T & A N G & P R & A N N \\ \text { pantá } & \text { 'panta } & \text { panta } & \text { panta } & ---- & ---- & ---\end{array}$

Todos los rubros presentan una aféresis de la primera sílaba del étimo portugués espantar (< lat. vulgar *expaventare).

9. Abrazar: port. 'abraçar'

$\begin{array}{lllllll}S A R & C V & G B & S T & A N G & P R & A N N \\ \text { baasa } & \text { 'brasa } & \text { barsa } & \text { blasa } & \text { ba } \theta \text { a } & \text { basa } & ----\end{array}$

Las palabras emparentadas muestran una aféresis vocálica respecto del étimo portugués abraçar.

10. Bailar: port. 'bailar'

$\begin{array}{llllllr}S A R & C V & G B & S T & A N G & P R & A N N \\ \text { bajá } & \text { 'bad3a } & \text { bad3a } & ---- & ---- & \text { baja } & \text { baja }\end{array}$

Los cognados constituyen el reflejo de un arcaísmo en portugués. Estas formas provienen del verbo balhar, derivado del latín ballare 'bailar'. El rubro actual del portugués bailar parece derivarse más bien del latín bajulare 'llevar a cuestas, mecer', introducido a la península ibérica a través del occitano (Corominas 1983).

\section{Especificidad de los criollos de base ibérica del Atlántico}

En los apartados anteriores, se ha podido establecer un número considerable de rubros que presentan particularidades que aparecen en los criollos de base ibérica americanos y en los criollos portugueses de África Occidental, pero que no se hallan en el portugués estándar. Esta cantidad corresponde a 27 palabras que ya habían sido reconstruidas para el pidgin afroportugués americano, 9 correspondencias de cognados entre el papiamento y los criollos africanos y 10 entre el saramaca y estos mismos criollos.

Se supone que muy probablemente estas similitudes se deben a que tanto los criollos ibéricos de América como los portugueses de África Occidental comparten un mismo origen genealógico.

En las listas mencionadas anteriormente, que contienen un total de 46 palabras, se puede ver que no todas las variedades comparadas presentan términos cognados para cada uno de los rubros. Los criollos ibéricos americanos comparten solamente un total 
de 27 términos emparentados con por lo menos uno de los criollos portugueses de la Alta Guinea (caboverdiano y kriol de Guinea-Bissau) y del Golfo de Guinea (saotomense, angolar, principense y annobonés). Esto quiere decir que existen 19 términos que los criollos de estas dos regiones de África Occidental no comparten entre sí.

Los datos históricos sugieren que los criollos de África Occidental pueden clasificarse en dos grandes grupos: los de Alta Guinea y los del Golfo de Guinea. El análisis de las listas anteriores parece avalar esta consideración, como puede notarse examinar los siguientes casos tomados de las listas presentadas antes:

\begin{tabular}{|c|c|c|c|c|c|c|}
\hline$C V$ & $G B$ & $S T$ & $A N G$ & $P R$ & $A N N$ & \\
\hline 'entra & entra & lentla & letfia & lenta & lentela & entrar \\
\hline papa'gaju & papagaja & papage & panpage & page & ----- & papagayo \\
\hline ir'mon & ermon & lumon & lumon & rima & name & hermano \\
\hline ba'riga & bariga & bega & beع́gá & buega & bega & barriga \\
\hline 'sol & sol & solo & Өolo & usolo & solo & sol \\
\hline ka'tfor & katfur & kaso & ka $\theta 0$ & kaso & zasolo & perro \\
\hline
\end{tabular}

A esta lista se pueden agregar los siguientes casos: ${ }^{53}$

\begin{tabular}{|c|c|c|c|c|c|c|}
\hline$C V$ & $G B$ & $S T$ & $A N G$ & $P R$ & $A N N$ & \\
\hline 'agu & jagu & awa & áwá & awa & awa & agua \\
\hline na'ris & naris & $\operatorname{lifi}$ & $\operatorname{lif} \mathrm{i}^{54}$ & irifi & lif & nariz \\
\hline ko'rason & korson & kroson & koӨon & kosan & kusan & corazón \\
\hline 'sal & sal & salu & $\theta$ alu & usalu & salu & sal \\
\hline 'lua & lua & nua & nunwan & ununa & onuinza & nube \\
\hline 'seu & seu & ose & on $\theta$ e & ose & ose & cielo \\
\hline 'leja & leja & inja & ninja & inja & nija & leña \\
\hline 'un & un & unwan & unwan & unwan & unja & uno \\
\hline 'kumpridu & kumpridu & loygo & loygo & loygo & longo & largo \\
\hline 'obi & obi & tindi & ende & tende & tindi & oír \\
\hline senta & senta & tason & $\operatorname{ta} \theta 0 n$ & tusan & tusan & sentarse \\
\hline
\end{tabular}

Es bastante evidente que las variedades de la Alta Guinea son más afines al portugués estándar que aquellas del Golfo de Guinea. La explicación para esto puede encontrarse al repasar los avatares históricos de la colonización de los territorios de África Occidental, tal como han sido presentados, sucintamente, en un apartado anterior. Aunque las Islas de Cabo Verde fueron descubiertas y colonizadas en una época temprana (desde mediados del siglo $\mathrm{XV}$ ), por los drásticos descensos de población, estas fueron repobladas prácticamente en los siglos XVIII y XIX desde Portugal. Esto condujo a que el criollo desarrollado en las islas fuera expuesto a una gran influencia del portugués estándar. 


\section{Conclusiones}

Los datos históricos permiten establecer que tanto los criollos de la Alta Guinea como los del Golfo de Guinea ya existirían con seguridad desde antes de la segunda mitad del siglo XVII y estarían estabilizados ya a principios del siglo XVIII, con excepción del caboverdiano de las Islas de Barlovento que habría sido establecido a finales del siglo XVIII. Precisamente, los autores han señalado que este criollo constituye una variedad bastante diferenciada incluso del caboverdiano de las Islas de Sotavento.

Desde el punto de vista estrictamente lingüístico, se ha podido comprobar que todas las variedades criollas comparadas (tanto los criollos ibéricos americanos como aquellos de África Occidental) comparten un número considerable de vocabulario (46 rubros) ${ }^{55}$ que presenta particularidades similares que no se encuentran en el portugués estándar. Se trata de términos cuyo origen puede atribuirse a variantes populares del portugués o a palabras que son consideradas actualmente arcaísmos en esta lengua. Esta similitud entre las variedades deja suponer que estas comparten un origen genealógico común.

Los datos lingüísticos no han permito, sin embargo, elucidar con claridad si los criollos ibéricos americanos son más afines a los criollos portugueses de la Alta Guinea o a los del Golfo de Guinea, ya que comparten con cada grupo un número semejante de cognados: 36 con los primeros y 37 con los segundos.

Por otro lado, la comparación entre los criollos de la Alta Guinea y los del Golfo de Guinea indica que estos constituyen dos grupos claramente diferenciados entre sí.

Por estas razones, se propone la siguiente clasificación de los criollos ibéricos del Atlántico, que incluye a todas las lenguas criollas ibéricas tanto de América como del África Occidental.

\section{Clasificación de las lenguas criollas ibéricas del Atlántico}

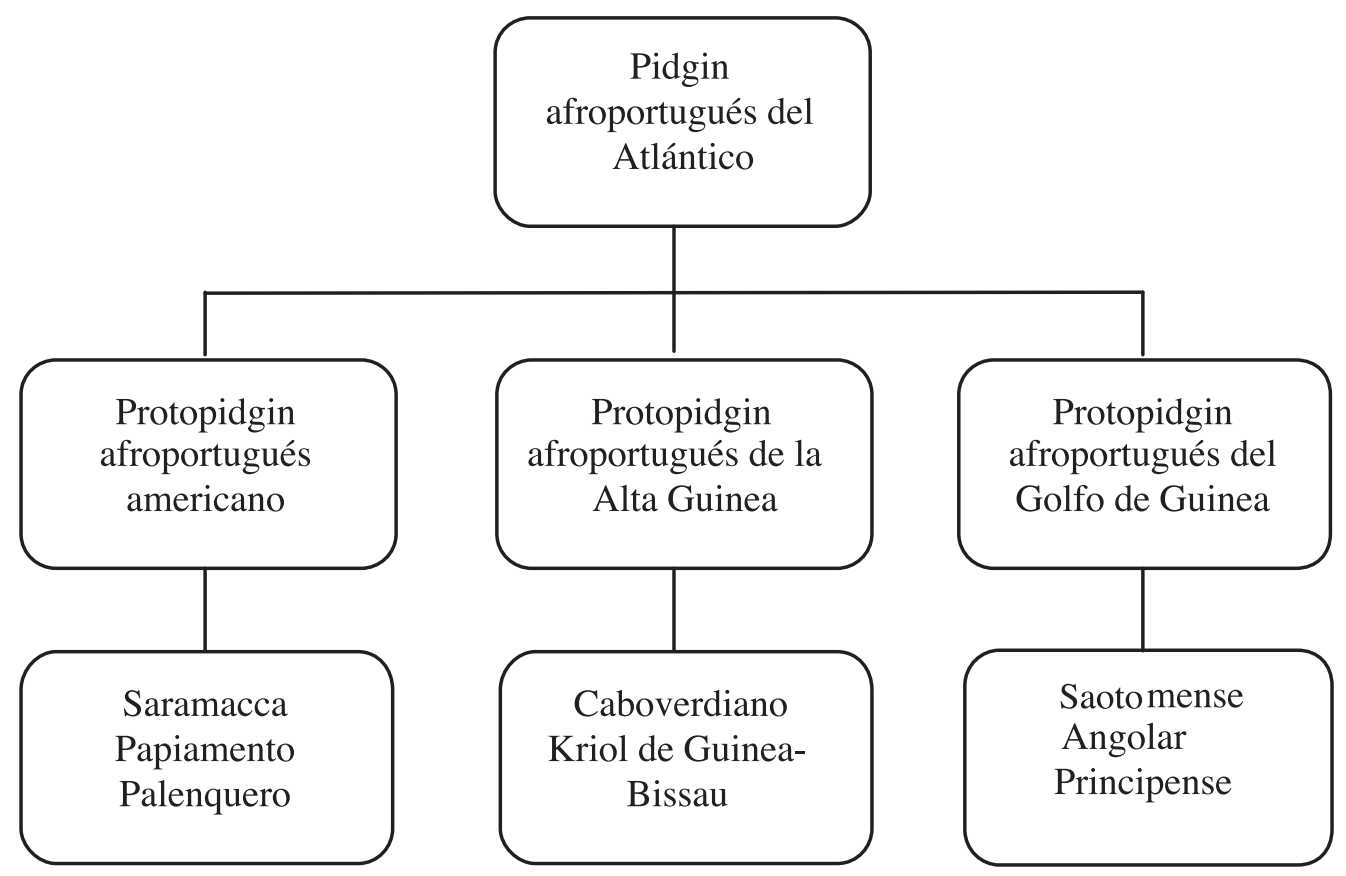




\section{Notas}

1. Algunos autores consideran que el papiamento tiene un origen puramente español, v.gr. Goodman 1987, Ladhams 1999a, 1999b, Parkwall 2000.

2. Los ejemplos son tomados de las siguientes fuentes: Maurer 1998b (papiamento), Maurer 1995 (angolar), Caudmont 1993 (macaense y papiá kristiáng), Clements 1996 (portugués de Korlai), Hancock 1975. Las transcripciones tienen un carácter fonológico, por supuesto, y utilizan el Alfabeto Fonético Internacional.

3. En esta lista se han omitido, en las respectivas lenguas, los términos que no son cognados. Esta omisión se señala con los guiones (-----).

4. $\quad$ Riemer (1779).

5. La aparición de la vocal final es un marcador de género masculino y se debe, presumiblemente, a influencia del español.

6. Los términos cognados se indican por medio de la letra negrita. Los guiones (-----) indican que no se encontró el rubro correspondiente en las fuentes consultadas. Las transcripciones tienen un carácter fonológico. Estas siguen las especificaciones que ofrecen los autores, pero se ha procurado estandarizarlas utilizando el Alfabeto Fonético Internacional. Se ha optado por señalar los suprasegmentales solo en dos lenguas. Se marcan el acento en el caso del caboverdiano (Quint-Abrial 1998) y los tonos altos en el angolar (Maurer 1995). De acuerdo con el análisis fonológico de Mané (2007) propuesto para los criollos del Golfo de Guinea, la nasalidad vocálica se interpreta siempre como la expresión fonética de una consonante nasal. Pero, a diferencia de este autor, en angolar, se ha preferido considerar [ s, z ] como alófonos de los fonemas / $\theta$, $\partial$ / respectivamente y no al revés, como este propone , pues su aparición está restringida a preceder al fonema / i /.

7. En esta lengua, el término más común es / 'ri /.

8. También existe la forma / ri /.

9. También existen las formas / ri, di /.

10. También existe la forma / rin /.

11. También existe la forma / ba /.

12. También existen las formas / ba, bomっ /.

13. También existe la forma / ba /.

14. También existe la forma / bomu /.

15. También existe la forma / 'durmi /.

16. También existe la forma / dumini /. 
17. También existen las formas / rumi, numi /.

18. También existe la forma / 'vumita /.

19. También existe la forma / vumita /.

20. También existe la forma / Jaba /.

21. También existe la forma / ki /.

22. Esto parece que no es así ya más en caboverdiano. Además, hay que mencionar que esta identidad de significado entre la preposición ‘con’ y la conjunción ‘y’ ocurre en otras lenguas criollas del Atlántico como el sranan y el criollo haitiano.

23. También existe la forma / nada /.

24. También existen las formas / nada, lada /.

25. También existe la forma / landa /.

26. También existe la forma / 'lembi /.

27. También existe la forma / maja /.

28. También existe la forma / relodzu /.

29. También existe la forma / purgunta /.

30. También existe la forma / pupunta /.

31. También existe la forma / dí bá /.

32. También existen las formas / ermun, armun /.

33. También existe la forma / lum /.

34 También existe la forma / namai ome /.

35. También existe la forma / 'sendi /.

36. También existe la forma / to /.

37. También existe la forma / ba /.

38. También existe la forma / $\theta \mathrm{a} \mathrm{ku} /$.

39. También existe la forma / ria /. 
40. También existen las formas / عta, ta /.

41. También existe la forma / bu /.

42. También existe la forma / fo /.

43. También existe la forma / o /.

44. También existe la forma / xasolu /.

45. También existe la forma / xasolu /.

46. También existen las formas / nala, nara /.

47. También existe la forma / mbigu /.

48. Riemer (1779). En saramacca, la forma actual es / buusé /.

49. También existe la forma / abri /.

50. También existe la forma / bla /.

51. También existe la forma / 'skodzi /.

52. También existe la forma / spanta /.

53. La lista corresponde a la inspección de 170 rubros presentados por Graham \& Graham (2003).

54. También existen las formas / rifi, difi /.

55. Hay que agregar a este número los 9 cognados compartidos solamente por los criollos del Golfo de Guinea, que son distintos del portugués estándar.

\section{Bibliografía}

Amaro's papiamentu project. http://papiamentu.donamaro.nl.

Arends, Jacques et al. (eds.). 1995. Pidgins and Creoles. An introduction. Amsterdam/ Filadelfia: Benjamins.

Bakker, Peter et al. 1995. ”Saramaccan". Arends et al. (eds.), 165- 78.

Bartens, Angela. 1995. Die iberoromanisch-basierten Kreolsprachen: Ansätze der linguistischen Beschreibung. Frankfurt/ Main: Peter Lang. 
Bickerton, Derek. 1999. “An old argument revisted”. Bruyn et al. (eds.), 253-256.

Bruyn, Adrienne et al. (eds.). 1999. Mengelwerk voor Muysken. Amsterdam: Universiteit van Amsterdam.

Cásseres, Solmery. 2005. Diccionario de la lengua afro palenquera-español. Cartagena de Indias: Pluma del Monpox.

Caudmont, Jean. 1992. "Die Lage der portugiesischen Sprache in Macau im 18. Jahrhundert anhand chinesischer Dokumente". Perl et al. (eds.), 9-43.

Clements, Clancy. 1992. "Foreigner talk ad the origins of pidgin Portuguese". Journal of Pidgin and Creole Languages. 7 (1): 75-92.

1996. The genesis of a language. The formation and development of Korlai Portuguese. Amsterdam/Filadelfia: Jonhn Benjamins.

1999. "La monogénesis y la formación de algunos criollos de base portuguesa". Zimmermann (ed.), 277-93.

2000. "Evidência para a existência de um pidgin português asiático". D’Andrade et al. (eds.), 185-200.

Corominas, Joan. 1983. Diccionario etimológico de la lengua castellana. Madrid: Gredos.

Díaz Alayón, Carmen (ed.). 1993. Homenaje a Pérez Vidal. Santa Cruz de Tenerife: Romero.

Ferraz, Luiz. 1987. "Portuguese Creoles of West Africa and Asia”. Gilbert et al. (eds.), 337-360.

Friedemann, Nina S. de \& Carlos Patiño. 1983. Lengua y sociedad en el palenque de San Basilio. Bogotá: Instituto Caro \& Cuervo.

Gadelii, Kart \& Anne Zribi-Hertz (eds.). 2007. Grammaires créoles et grammaire comparative. Saint-Denis: Presses Universitaires de Vincennes.

Gilbert, Glenn (ed.). 1987. Pidgin and Creole languages: Essays in memory of John E. Reinecke. Honolulu: University of Hawaii Press.

Good, Jeff. 2009. “Loanwords in Saramaccan”. En Martin Haspelmath \& Uri Tadmoor (eds.) Loanwords in the world's languages: A comparative handbook. Mouton: De Gruyter. http://www.acsu.buffalo.edu/ jcgood/publications.html.

Goodman, Morris. 1987. “The Portuguese element in American Creoles”. Gilbert (ed.), 361-405. 
Graham, Steve \& Trina Graham. 2003. "West Africa lusolexed creoles list file documentation". Summer Institute of Linguistics (SIL International). http://www.sil.org/ silesr/2004/silesr2004-012.htm.

Granda, Germán de. 1970. “Un temprano testimonio sobre las hablas 'criollas' en África y América”. Thesaurus 25 (1), 1-11

1974. "El repertorio lingüístico de los sefarditas de Curacao durante los siglos XVII y XVIII y el problema del origen del papiamento". Romance Philology 28: 1-16.

Grimes, Joseph. (ed.). 1972. Languages of the Guianas. México: SIL.

Hagemeijer, Tjerk. 2009. “As línguas de S. Tomé e Príncipe”. Revista de Crioulos de Base Lexical Portuguesa y Espanhola. 1.1. http://rcblpe.sftw.umac.mo/HOME_SPAN_ (RCBLPE)_1_content.html.

[por aparecer] "The Gulf of Guinea Creoles: genetic and typological relations". Journal of Pidgin and Creole Languages. http://alfclul.clul.ul.pt/crpc/site_anagrama/ files/JPCL_typology_28-07-10.pdf.

Hancock, Ian. 1975. “Malacca Creole Portuguese: Asian, African or European”. Anthropological Linguistics. 17: 211-236.

Hasiver, Jay \& Kevin MacDonald (eds.). 2006. African re-genesis: Confronting social issues in the diaspora. Londres: University College London Press.

Holm, John.1989. Pidgins and creoles. Vol. 2, Cambridge: Cambridge University Press.

Huber, Magnus \& Mikael Parkvall (eds.). 1999. Spreading the word. Londres: Westminter University Press.

Huttar, George. 1972. “A comparative word list for Djuka”. Grimes (ed.), 12-21.

Kouwenberg, Silvia \& Pieter Muysken.1995. "Papiamento". Arends et al. (eds.), 205-18.

Ladhams, John. 1999a. "The Pernanbuco connection? An examination of the nature and origin of the Portuguese elements in the Surinam Creoles". Huber \& Parkvall (eds.), 209-40.

1999b. “Response to Norval Smith”. Huber \& Parkvall (eds.), 299-304.

Lipski, John. 1994. "El lenguaje afroperuano: eslabón entre África y América”. Anuario de Lingüística Hispánica 10: 79-216.

2002. "Génesis y evolución de la cópula en los criollos afroibéricos". Moñino \& Schwegler (eds.), 2002: 65-101. 
Lopes da Silva, Baltasar. 1957. O dialecto crioulo de Cabo Verde. Lisboa: Imprensa Nacional de Lisboa.

Lorenzino, Gerardo. 2007. "Linguistic, historical and ethnographic evidence on the formation of the angolares, a marron-descendant community in São Tomé (West Africa)". Portuguese Studies Review 15: 193-226.

Machado, José Pedro. 1956. Dicionário etimológico da língua portuguesa. Lisboa: Confluência.

Mané, Djiby. 2007. “Os crioulos portugueses do Golfo da Guiné: Quatro línguas diferentes ou dialetos de uma mesma língua?” Universidade de Brasília: Tesis doctoral.

Maurer, Philippe. 1995. L'angolar. Un créole afro-portugais parlé à São Tomé. Hamburgo: Heltmut Buske Verlag.

1998a. "El papiamento de Curazao". Perl \& Schwegler (eds.), 139-218.

1998b. Les modifications temporelles et modales du verbe dans le papiamento de Curaçao. Avec une antologie et un vocabulaire papiamento-français. Hamburgo: Helmut Buske.

McWhorter, John. 1999. “The afrogenesis hypothesis of plantation Creole origin”. Huber \& Parkvall (eds.), 111-52.

Megenney, William.1983. "La influencia del portugués en el palenquero colombiano". Thesaurus 28, 548-563.

1986. El palenquero. Un lenguaje post-criollo de Colombia. Bogotá: Instituto.

Moñino, Yves. 2007. "Les rôles du substrat dans les créoles et les langues secrètes: le cas du palenquero, créole espagnol de Colombie”. Gadelii \& Zribi-Hertz (eds.), 49-72.

Moñino, Yves \& Armin Schwegler (eds.). 2002. Palenque, Cartagena y Afro-Caribe. Historia y lengua. Tübingen: Niemeyer.

Naro, Anthony.1978. "A study of the origins of pidginization”. Language 54 (2), 314-347.

Papiamento-English/ English-Papiamento lexicon. http://www.ats-group.net/dictionaries/ dictionary-english-papiamento.html.

Parkvall, Mikael. 2000. Out of Africa. African influences in Atlantic Creoles. Londres: Battlebridge Publications.

Patiño, Carlos. 2002. “Sobre origen [sic] y composición del criollo palenquero”. Moñino \& Schwegler (eds.), 21-49. 
Perl, Matthias. 1987. “Habla bozal -eine spanisch-basierte Kreolsprache?”. Perl (ed.), 1-16.

1989a. "Portugiesisch und Crioulo in Afrika. Geschichte. Grammatik. Lexik. Sprachentwicklung”. Leipzig: Karl-Marx-Universität.

1989b.“Zur Präsenz des kreolisierten Portugiesisch in der Karibik: Ein Beitrag zur Dialektologie des karibishen Spanisch“. Beiträge zur romanischen Philologie 28: 131-148.

1990. "A reevaluation of the importance of early pidgin/creole Portuguese". Journal of Pidgin and Creole languages. 5: 125-30.

1998. “Introducción”. Perl \& Schwegler (eds.), 1-24.

Perl, Matthias (ed.). 1987. Beiträge zur Afrolusitanistik und Kreolistik. Linguitische Studien. Berlín: Zentralinstitut für Sprachwissenschaft.

Perl, Matthias \& Armin Schwegler (eds.).1998. América negra. Panorámica actual de los estudios lingüisticos sobre variedades hispanas, portuguesas y criollas. Frankfurt/ Madrid: Vervuert/Iberoamericana.

Perl, Matthias et al. (eds.).1993. Portugiesich-basierte Kreolsprachen. Frankfurt: TFM.

Quint-Abrial, Nicolás. 1998. Dicionário caboverdiano- português. Variante de Santiago. Lisboa: Verbalis.

Portilla, Mario. 2007. "Reconstrucción fonológica del pidgin afroportugués americano: Las vocales". Revista de Filología y Lingüística de la Universidad de Costa Rica. 33(2): 179-203.

2008a. "Protopidgin afroportugués americano". Revista Internacional de Lingüística Iberoamericana (RILI). 6(1): 161-83.

2008b. "Reconstrucción fonológica del pidgin afroportugués americano: Las consonantes". Revista de Filología y Lingüística de la Universidad de Costa Rica. 34(1): 157-192.

2009. “Tono y acento en el pidgin afroportugués americano". Revista de Filología y Lingüística de la Universidad de Costa Rica. 35(1): 139-177.

Riemer, Johann Andreas. 1779. Wörterbuch zur Erlernung der Saramakka-Neger-Sprache. http://www.sil.org/americas/suriname/Riemer/National/RiemerNLDict.

Saramaccan - English Dictionary. http://www.sil.org/americas/suriname/Saramaccan/English/ SaramEngDictIndex). 
Scantamburlo, Luigi. 1981. Gramática e dicionário da língua criol da Guiné-Bissau (Gcr). Bolonia: Editrice Missionaria Italiana.

Schwegler, Armin. 1991. "Zur Problematik der afroportugiesischen Kontaksprache in Amerika: Nenes aus El Palenque de San Basilio (Kolumbien)”. Lusorama 15: 54-79.

1993. "Rasgos (afro-) portugueses en el criollo de Palenque de San Basilio (Colombia)". Díaz Alayón (ed.), 1993:667-696.

1998. "El palenquero". Perl \& Schwegler (eds.), 1998: 218-91.

2002. "El vocabulario africano de Palenque (Colombia). Compendio alfabético de palabras (con etimologías)". En: Moñino \& Schwegler (eds.), 171-226.

2006. "Bantu elements in Palenque (Colombia): Anthropological, archeological, and Linguistic evidence”. En: Hasiver \& MacDonald (eds.), 204-222.

Smith, Norval. 1995. "An annotated list of creoles, pidgins, and mixed languages". Arends et al. (eds.), 331-374.

Stolz, Thomas. 1987. "Verbale morphosyntax der portugiesisch-basierten Kreols". Iberoamericana 11: 35-59.

Thiele, Petra. 1991. Kaboverdianu. Elementaria seiner TMA-Morphosyntax im lusokreolischen Vergleich. Bochum: Brockmeyer.

Whinnom, Keith. 1965. “Origin of European-based creoles and pidgins”. Orbis 14(2): 509-27.

Zimmermann, Klaus (ed.). 1999. Las lenguas criollas de base lexical española y portuguesa. Frankfurt/Madrid: Vervuert/Iberoamericana. 